\title{
RARE CAUSE OF SOLITARY PULMONARY NODULE AND DYSPNOEA IN MIDDLE-AGE: PULMONARY ARTERIO-VENOUS MALFORMATION
}

Ashima Datey ${ }^{1}$, Mahesh Marupakala ${ }^{2}$, Cecilia Vanisha ${ }^{3}$, Pradyut Waghray ${ }^{4}$, Praveen $K^{5}$.

1. Pulmonologist, Department of Pulmonology, Eesha Hospitals, Hyderbad.

2. Intensivist, Department of Anesthesiology, Eesha Hospitals, Hyderbad.

3. Critical care specialist, Department of Anesthesiology, Eesha Hospitals, Hyderbad.

4. Pulmonologist, Department of Pulmonology, Eesha Hospitals, Hyderbad.

5. Consultant Pulmonologist, Department of Pulmonology, Eesha Hospitals, Hyderbad.

\section{CORRESPONDING AUTHOR}

\author{
Dr. Ashima Datey, \\ D2, 231, Kanthishikhara Apartments, \\ Punjagutta, \\ Hyderabad 500082. \\ Email-ashima_aries@yahoo.com
}

\section{HOW TO CITE THIS ARTICLE:}

Ashima Datey, Mahesh Marupakala, Cecilia Vanisha, Pradyut Waghray, Praveen K. "Rare Cause of Solitary Pulmonary Nodule and Dyspnoea in Middle-age: Pulmonary Arterio-Venous Malformation". Journal of Evolution of Medical and Dental Sciences 2013; Vol2, Issue 26, July 1; Page: 4752-4755.

\begin{abstract}
Pulmonary arteriovenous malformations are caused by abnormal communications between pulmonary arteries and pulmonary veins, which are most commonly congenital in nature. Although these lesions are quite uncommon, they are an important part of the differential diagnosis of common pulmonary problems such as hypoxemia and pulmonary nodules. ${ }^{1}$ We report the case of a middle aged lady with subacute onset of mild breathlessness and cough, who was found to be cyanotic, severely hypoxic and hypoxemic on investigation. Thorough workup revealed solitary large pulmonary arteriovenous malformation, without involvement of any other symptoms or family history. She underwent embolo-therapy and had relief of symptoms. This case underlines a rare cause of a very common symptom like dyspnoea, and reiterates the need for thorough investigation and workup.
\end{abstract}

KEYWORDS: Pulmonary Arteriovenous malformations, Solitary Pulmonary Nodule, Increased A-a gradient, cyanosis

INTRODUCTION: Pulmonary arteriovenous malformations (PAVM) are rare pulmonary vascular anomalies. Although most patients are asymptomatic, PAVMs can cause dyspnoea from right-to-left shunt. ${ }^{2}$ PAVMs are a rare and benign cause of Solitary pulmonary nodules (SPN) and should be considered in patients with dyspnoea in setting of SPN.

CASE REPORT: A 53 year old female came walking for consultation with complaints of shortness of breath on exertion (grade II -MMRC, more in erect posture) and cough with scanty mucoid expectoration since 2-3 months. She was conscious, alert and afebrile, had pedal edema and facial puffiness. She was found to have central cyanosis, hypoxia on room air with $\mathrm{SpO}_{2}-35 \%$. Vital signs 
were HR-115/min. BP-150/80 mmHg. RR-30/min. Chest examination revealed normal breath sounds. All other systems were normal. ABG done on admission revealed hypoxemic respiratory failure with A-a gradient of 150. Routine blood investigations were normal. 2D echo showed RA/RV dilatation and moderate PAH suggestive of cor-pulmonale. Chest X-ray showed circumscribed rounded opacity in right lower zone. Patient was treated with high flow oxygen enrichment devices to ensure maximal $0_{2}$ delivery. As hypoxemia did not improve with HAFOE therapy, a trial of BIPAP was given which failed to improve oxygenation.

In view of persistent hypoxemia unresponsive to $\mathrm{O}_{2}$ therapy and increased $\mathrm{A}$-a gradient we decided to do a CT pulmonary angiogram to evaluate for shunt pathology. CT pulmonary angiogram showed large pulmonary A-V fistula in right lower lobe with dilated single pulmonary arterial branch communicating with segmental pulmonary vein through a large aneurysmal dilatation measuring 5x $4.3 \mathrm{cms}$, protruding into pleural cavity. Patient underwent embolotherapy and had significant improvement of arterial blood gases and symptomatology.

DISCUSSION: Direct communications between the branches of pulmonary artery and pulmonary veins, without an intervening pulmonary bed, are probably the most common anomalies of the pulmonary vascular tree. They are variously called as pulmonary arteriovenous fistula, pulmonary arteriovenous malformation (PAVM), pulmonary arteriovenous aneurysm (PAVA), pulmonary angioma, arteriovenous angiomatosis, cavernous hemangiomas, and pulmonary hamartomas. The etiology of PAVM is unknown. They are most commonly congenital, more common in women and tend to have a familial preponderance. They may remain asymptomatic and undiagnosed in approximately half of the instances, only diagnosed at autopsy.

Pulmonary AV malformations can be classified as simple when there is a single draining artery and vein, or complex when there are more than one feeding and draining vessels. Most (approximately 90\%) are simple as shown by helical CT scanning. Detailed classification has been described by Anabtawi et al3, giving 5 categories of PAVMs. Common symptoms of PAVMs are dyspnoea, epistaxis, haemoptysis, palpitation, chest pain, cough etc. Examination may show signs such as bruit/thrill, clubbing, cyanosis, telangiectasia, polycythemia, anaemia etc. A rare and interesting finding of platypnea - orthodeoxia, where the patient is breathless and hypoxic on sitting, and improves on lying down may be present, as was seen in our case. Pulmonary A-V malformation may remain undiagnosed in life, or may present with complications such as hypoxaemia, intrabronchial rupture, haemoptysis, intrapleural rupture, haemothorax, paradoxical embolisation, polycythemia, pulmonary hypertension, endocarditis, transient ischaemic attacks etc.

Chest radiography is an important diagnostic tool not only in diagnosis but also in the follow up of patients with a PAVM. A plain chest radiograph shows abnormalities in about $98 \%$ of patients. The classic radiographic features of PAVM are a round or oval sharply defined mass of uniform density, frequently lobulated, and ranging in size from 1-5 cm in diameter; two thirds are located in the lower lobes, rarely the connecting vessel may be seen radiating from the hilum. Contrast echocardiography, contrast enhanced CT scans or CT pulmonary angiography are useful tools for diagnosis. Radionuclide scanning may be used where available.

Treatment of PAVM has been described in history by surgical removal. Recent advances have made minimally invasive methods such as balloon embolo-therapy and coiling possible. Recent reports of video assisted thoracoscopic techniques for removal of small malformations have also 
been described. Our patient successfully underwent balloon embolo-therapy and was discharged. She is being followed up in out-patient department and has improved oxygenation and no complications at 1 month after procedure.

CONCLUSION: Pulmonary Arteriovenous Malformation is a rare cause of dyspnoea and hypoxemia in adults. It is an uncommon cause of Solitary Pulmonary nodule, and requires diligent workup and investigation for identification. Early identification of PAVM in symptomatic patient can prevent dreaded complications and must be considered in differential diagnosis of solitary pulmonary nodule with dyspnoea.

\section{REFERENCES:}

1. James R. Gossage, Ghassan Kanj "Pulmonary Arteriovenous Malformations", American Journal of Respiratory and Critical Care Medicine, Vol. 158, No. 2 (1998), pp. 643-661. doi: 10.1164/ajrccm.158.2.9711041

2. I Khurshid, G H Downie. Pulmonary arteriovenous malformation : Postgrad Med J 2002; 78:191-197

3. Anabtawi IN, Ellison RG, Ellison LT. Pulmonary arteriovenous aneurysms and fistulas. Ann Thorac Surg 1965; 1:277-85.

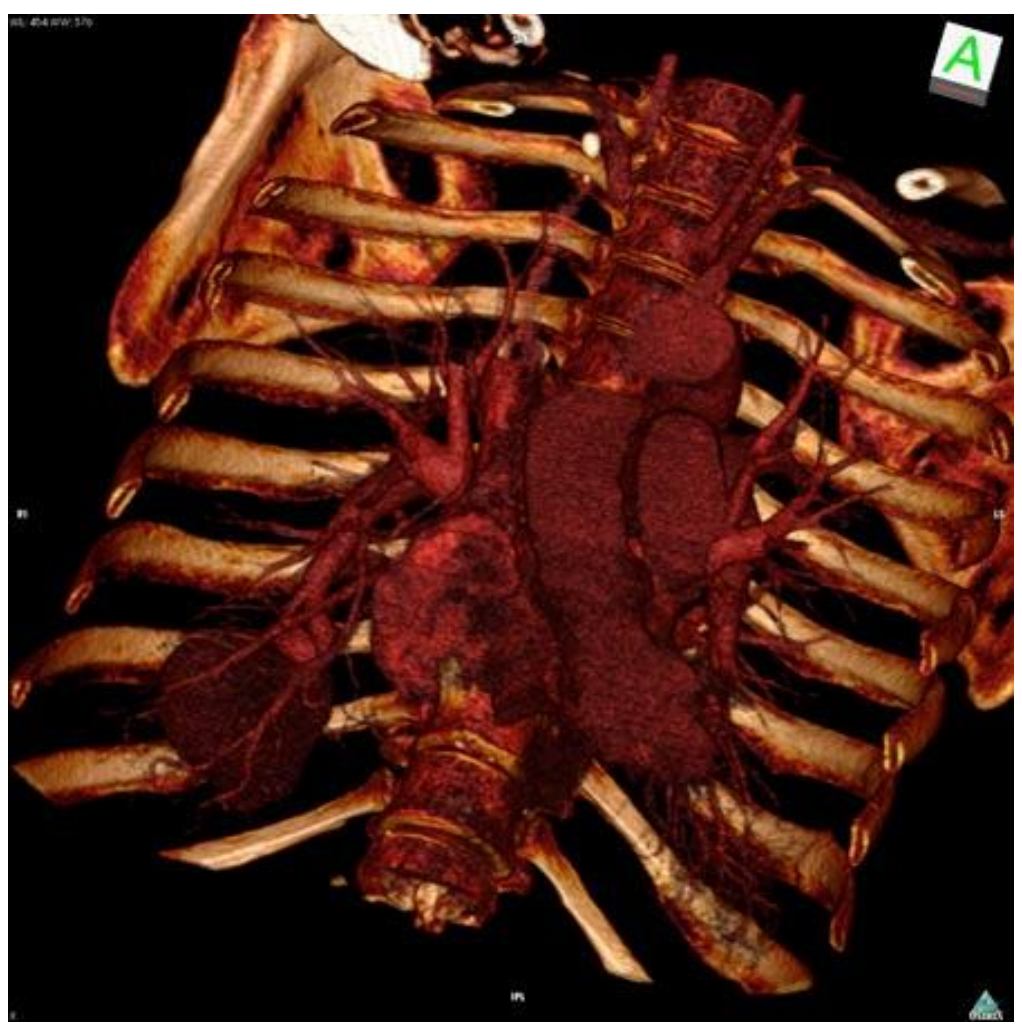

Image 1: 3D reconstruction of PAVM. 


\section{CASE REPORT}

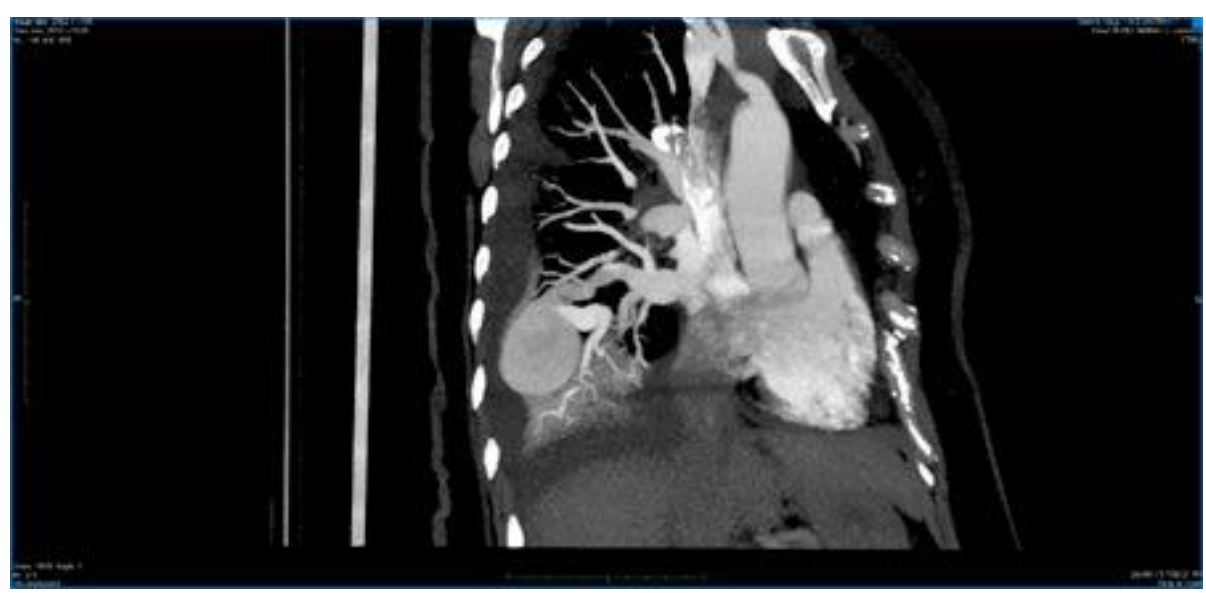

Image 2: CECT Chest showing PAVM. 